\title{
Does professor-student trust improve motivation and perceived performance?
}

La relación de confianza entre profesor y alumno, ¿̇mejora la motivación y los resultados?

Katharina Hamann (katharina.hamann@de.ey.com)

Ernst \& Young GmbH, Hamburg (Germany).

Diego Maldonado (diego.juts@gmail.com)

IE University, Segovia (Spain)

María del Pilar Sánchez (m.sanchez.prof@ufv.es)

Universidad Francisco de Victoria, Madrid (Spain)

David Pascual Ezama (david.pascual@ccee.ucm.es) Corresponding author

Universidad Complutense de Madrid, Madrid (Spain)

http://dx.doi.org/10.12795/EDUCADE.2017.108.03

RESUMEN: Nuestro trabajo analiza el efecto que sobre la motivación de los estudiantes tiene la relación de confianza tanto personal como académica entre el profesor y el estudiante así como la percepción que éste tiene de su desempeño. Para ello hemos utilizado una encuesta on line en la que pedimos a los estudiantes universitarios que evalúen a sus profesores como un todo usando una escala de Likert. Las variables independientes fueron la confianza académica y la confianza personal, mientras que las variables dependientes fueron la motivación y el desempeño percibido. Los resultados mostraron una correlación positiva entre la confianza tanto académica como personal en relación con la motivación y el rendimiento percibido. Las ramificaciones de nuestro estudio sobre investigaciones futuras impulsan la idea de que la confianza debe ser vista desde diferentes perspectivas y que es una parte implícita de las habilidades de enseñanza.

PALABRAS CLAVE: aprendizaje, confianza, relación profesor-alumno, motivación, resultados académicos.

\begin{abstract}
Our study takes into account the way in which both academic and personal trust has an effect on the motivation of students and their perceived performance. To do this we sent an online survey in which we asked higher education students to evaluate their professors as a whole using a Likert scale. The independent variables were academic trust and personal trust, whilst the dependent variables were motivation and perceived performance. The results showed a positive correlation between academic trust and motivation, as well as with perceived performance. The same result was achieved when studying personal trust in regards to motivation and perceived performance. This implies that there is an important positive relationship between trust and the general performance of students in class. The ramifications of our study on future research push for the idea that trust must be seen from differing perspectives, and that it is an implicit part of teaching skills.
\end{abstract}

KEYWORDS: learning, confidence, teacher-student relationship, motivation, academic performance

Artículo. Recibido: 07-03-17 - Versión revisada: 18-07-17, Aceptado: 19-07-17

Licencia Creative Commons BY NC ND $\cdot 2017 \cdot$ Asociación Española de Contabilidad y Administración de Empresas - AECA 


\section{INTRODUCTION}

It is common to ask yourself since childhood why you perform at a higher level in some classes than in others. Another common question is why you find that certain classes motivate you more, or are more 'fun' than others. Our study tackles these questions through the notion of trust. We believe that strong student-professor trust relationships enhance participation, as well as autonomy during and out of the classroom. As the trust relationship is different according to the educational levels we focus our attention in higher education taking into account that the professor-student relations ship is different than in the preliminary and secondary school.

Previous studies regarding trust between a teacher and a student focus on the extent to which students trust their teachers. Researchers have looked at this topic from various angles and contexts. Firstly, the effect of trust on students has been analyzed in the context of academic achievement. Following, it has been studied in the context of student's social lives, and finally in the context of how it affects general school culture. It has been shown that teacher-student trust improves student's academic performance and motivates learning (Tschannen-Moran \& Hoy, 2000: 584-585).

These findings are particularly important in order to encourage participation in class, socialization between students, and admittance of lack of understanding during lectures. It is also believed to be significant to allow students to share opinions on certain improvements that they believe would be beneficial to the class. However, the most vital fact regarding the significance of studies related to student-teacher trust is that "trust is an integral component for culturally sensitive pedagogy" (Jackson, 1994: 300-302).

Some research suggests that teachers who demonstrate a trusting relationship with their students in financial accounting classes, offering the possibility to participate in research project in accounting, improves both in the acquisition of knowledge as in the acquisition of competences (Sánchez-Martín, et al. 2014: 35-37). Another trust relationship in an accounting class demonstrate that when the information provide to the student regarding the way in which they are evaluated and therefore, when they are better informed, make a greater effort in the proposed activities and, therefore, an improvement in his academic results (Pascual-Ezama, et al. 2017: 52-53). On the other hand, other research suggests that teachers who do not demonstrate a trusting relationship with their students, and in fact sometimes mistrust them, have a tendency of using more fear related authority in order to keep control over the classroom and be able to teach (Cothran \& Ennis, 1997: 543-545). Trust is an attitude of optimism that the goodwill of competence of another will the expectation that the one trusted will be directly and favorably moved by the thought that we are counting on her (Jones, 1996; 4-5). Following, a good trust bond between teachers and students motivates the teacher to adjust balance of power within the classroom in order to allow autonomy towards the students (Tschannen-Moran, \& Hoy, 2000: 551-554); Eshel \& Kohavi, 2003: 250-252; Byrk \& Schneider, 1996: 9-16).

Finally, studies advocate that trust in the teacher-student relationship is very helpful in improving students' adjustment into the school, their contribution to after-school activities, and a general avoidance of bullying or other counterproductive behavior that may happen in schools (Wentzel, 1991: 1069-1071; Van Petegen, et.al, 2006: 284286; Baker, Grant, \& Morlock, 2008: 5-7; Rosenfeld, Richman, \& Bowen, 1998: 49-52).

\section{OBJECTIVE}

educade, no 8,2017, p. 22 
Due to the various reasons listed above, the purpose of our study is to find a plausible correlation between differing types of trust that university students have with their professors, and the way in which this trust affects motivation and perceived performance. Our hypothesis is that personal trust as a motivating element would render a curvilinear relationship (CR), in the same way that it would affect a student's perceived performance. On the other hand, academic trust would maintain a constant positive correlation for both motivation and perceived performance. Therefore, the null hypothesis would be that there is no correlation between motivation and personal trust as well as no connection between perceived performance and personal trust. The last part of the null hypothesis would assume that there is either no connection or a negative correlation between academic trust and the two dependent variables, motivation and perceived performance. Trust is studied from the perspective of the students, as it is their motivation and perceived performance that we are measuring. The trust and motivation scales used were taken from a 2008 study regarding trust and motivation in high school. (Corrigan \& Chapman, 2008: vol. 9). The perceived performance scale was also taken from this study; although previously it was called the Learner Empowerment Scale. However, one of the limitations of the sample used by the researchers was that they were students out of high school. Therefore, they had to recall the level of trust they had with their professors, as well as their level of motivation. We decided to eradicate this limitation by using students who are still in university, in order to have a present and fresh idea of their trust and motivation. Furthermore, we chose to do a cross-cultural study in the context of these countries. This was done in order to eliminate possible biases between student-teacher relationships, or the general working ethic of students; both being external variables that could affect our design.

Following, our independent variable, "trust", as a concept is generally thought of as singular and universal in all contexts. This is something we believe must be defined and differentiated for differing frameworks. As we are defining a teacher-student relationship we decided that the first type of trust being measured should be academic trust. Academic is defined as "[something] based on formal study especially at an institution of higher learning" (Merriam-Webster, 2013). In the context of this paper the most important point of this definition is the fact that it has to do with formal studying, meaning that there is a methodology behind learning. The second part of the variable is trust. It is defined as "assured reliance on the character, ability, strength, or truth of someone or something" (Merriam-Webster, 2013), and it holds significance within its traits of assured reliance and ability. Combining the selected points, our own definition would be "The assured reliance and ability to apply the methodology of formal studying". The second notion of trust is what we refer to as personal trust. Using the definition of personal, "of, relating to, or affecting a particular person" (MerriamWebster, 2013) and relating it to the previous definition of trust, we can combine them to render the definition "the ability and character to relate to and affect a particular person positively". Of course this would have to be seen in the educational context.

Our dependent variables, motivation' and perceived performance, were measured based on the student's own perception regarding their current success within the class. In order to quantify these phenomena a Likert scale was used. This Likert scale was applied to two previously used questionnaires known as the Student Motivation Scale (SMS), and the Learner Empowerment Measure (LEM) (Corrigan \& Chapman, 2008: vol.9). 


\section{METHOD}

\section{Participants}

Seventy-three international individuals completed the online instrument of this study. Participants were contacted by IE student office Facebook, the official page of IE University undergraduate education in the social networks with more than one thousand and seven hundred students. We published in the social network our study so that the members who wanted to participate could complete our questionnaire. They ranged in age from 18 years to 24 years, with a mean age of 20.37 years (SD 1.89). Gender-wise, it can be said that there were a lot more female participants (63.01\%) than male participants (36.99\%) that is representative of the gender levels in the University. Besides looking at their gender and age, we also considered the participants level of education. In general, the sample was studding a university degree mainly in economy and psychology focus in human resources. The majority of the sample -91.78 $\%$ - was currently enrolled in University while $8.22 \%$ reported to have obtained their Bachelor. All participants had a sufficient knowledge of English to participate in the study even if their level varied. $27.40 \%$ reported to be native-English speakers, $57.53 \%$ fluent and $10.96 \%$ proficient, whereas only $4.11 \%$ reported more difficulty with English (2.73\% said they could get around and $1.37 \%$ said they could understand a few words).

\section{Procedure}

For this study a total number of 73 people, between the ages of $18-24$, completed a 31-question survey. This sample was obtained, through the distribution of an online survey via the Internet. E-mail addresses and social network such as Facebook, were used to circulate the survey. Each of our contacts was then asked to send the survey further to one of his or her friends. Therefore when considering the sampling rate, it can be said that it is completely unknown how many of these contact actually completed the survey. Yet, it can be said that some of them must have followed our request to further distribute the survey; otherwise this completely international sample could not have been obtained.

The sampling technique we chose is called "the Snowball effect" (Stangor, 2011), and was used to gain more widespread information. The fact that the survey was online facilitated this process, as it did not require the experimenters to be in direct contact with the participants of the study. Each of the participants' answers was then recorded in an online database, to which both experimenters had access to regardless of where they were. None of the participants had access to this database or were able to check the results afterwards.

The instrument itself consisted of 31 questions, six collecting demographic information about the sample, 17 about academic and personal trust, 9 about perceived performance and a set of 5 questions measuring the student's motivation. (Corrigan, \& Chapman, 2008). The measures for these specific categories were taken from an already existing survey that was published in 2008. Some questions were altered to fit the purpose of our study. The participants were not given a specific timeframe in which to complete the survey but were told a specific date by which the survey had to be completed. The experimenters distributed the survey without giving the participants any further information about the study itself. No study-based questions, from the participants were answered and the participants were not debriefed after completing the questionnaire. 


\section{Measures}

For this study, we looked at the relationship between personal and academic trust in professors and students motivation and perceived performance. To do so, a survey was sent out including a total of 31 questions. The majority of questions were taken from an already existing survey published by Corrigan and Chapman (2008). The reason behind using such a questionnaire as opposed to other trust surveys is due to our emphasis on the student's perspective regarding the trust they share with their teachers. Other scales that we found focused on the trust the teacher had towards his or her students. One of these was a Tschannen-Moran \& Hoy scale created in 1999. As the study using it describes, "this 5 - point scale measures teacher's general willingness to be vulnerable to the students and teachers' perceptions of students' benevolence, reliability, competence, openness, and honesty" (Van Maele \& Van Houtte, 2011: 86-95). This scale would have been of great use if it were not for the fact that it focused on the staff. Furthermore, trust in the context of education is more likely to be a result of the manner by which a teacher treats the student. Seeing this from the student's perspective, it would be the way the teacher communicates with him or her as time progresses (Wooten \& McCroskey, 1996: 95-98). The survey of these authors was then proofread, to minimize experimental error and to ensure that they did not contain any imprecise language or too technical terms. Any questions falling into that category were improved and others were added to differentiate between academic and personal trust. Some questions also had to be eliminated to fit the purpose of our study. Any loaded, double-barreled and yay and nay saying questions were avoided. The questions themselves were split up into three categories. The exact measures used are as follows.

The Individualized Trust Scale (ITS) was a 5-point likert scale adaptation of Corrigan and Chapman (2008). Besides that, we coded all individual trust variables, according to academic and personal trust. Some of them did not fit into either category, which is why we eliminated them and added others instead. Participants complete the same questionnaire two times, with a two points of view respect to the professor: Academically and Personally. (See appendix for the final set of questions used)

The Learner Empowerment Measure (LEM), which was altered to focus on perceived performance, was initially published by Corrigan and Chapman (2008) to look at learner empowerment. Due to the fact that this study is about perceived performance and therefore rather a self-evaluation of the student's performance, the learner empowerment scale was renamed and called, perceived performance.

The Student Motivation Scale (SMS; Corrigan and Chapman, 2008) was used without any change in the items. All we altered was the 7-point semantic scale to a 5-point Likert scale, to have a consistent measure within our study. Another factor that we decided to change due to reliability purposes is the order in which each of the variables was asked. The initial study had all positive factors on one side and all negative factors on the other. In order to avoid the participants from simply clicking the one column only without reading properly, we counterbalanced the questions. (See appendix for the final set of questions used) 


\section{RESULTS}

\section{Descriptive Statistics}

In this study, the relationships between student's academic as well as personal trust relationship with the professor and motivation as well as perceived performance were examined.

Table 1: Descriptive statistics for the four measures: academic trust, personal trust, motivation and perceived performance

\begin{tabular}{|l|c|c|c|}
\hline & N & Mean & Standard deviation \\
\hline Academic Trust & 73 & 3.76 & .50 \\
\hline Personal Trust & 73 & 3.81 & .54 \\
\hline Motivation & 73 & 3.86 & .74 \\
\hline Perceived Performance & 73 & 3.78 & .53 \\
\hline
\end{tabular}

Table 1 shows the means and standard deviation for the four measures on the instrument. All of them are out of a 5-point Likert scale. In this study's sample, the mean for the first independent variable, academic trust, was 3.76 (SD = 0.50) and for the other independent variable, personal trust, it was 3.81 (SD $=0.54)$. The mean of the two dependent variables was $3.86(S D=0.74)$ for motivation and 3.77 (SD $=0.53$ ). Having said that, from the learner empowerment scale we select 9 items that best defined perceived performance, and eliminated the rest that was only looking at learner empowerment and had nothing to do with the variable we were interested in. Perceive performance is a dimension of the questionnaire that is previously reliable. In terms of the initial study, this means that instead of looking at the three dimensions: impact, meaningfulness, and competence; we only considered impact and competence and eliminated any questions to do with the meaningfulness of the class. This is because they did not fit our definition of perceived performance, explained in the introduction. As for the last one, we again decided to reduce the Likert scale from a 7-point one to a 5-point Likert scale, as we believed that this would make our survey as well as the results clearer for perceived performance. Due to the fact, that for all of the variables, the same scale was used, the different variables can be compared more easily. Henceforth, when looking at the different means it can be said that in general the participants showed high levels in all four measures. In other words there was high academic as well as personal trust but also high motivation and high-perceived performance. To be more precise, the level of motivation was highest, followed by the level of personal trust, academic trust and lastly perceived performance. Next, we examined the correlation between the 4 measures. For this we are first looking at the impact of personal trust on perceived performance and motivation and after that we consider the impact of academic trust rather than personal trust.

\section{Inferential Statistics}

When looking at Table 2, it can be said that all correlations showed a weak-medium, positive relationship and that all relationships were significant at the .01 level. However, in order to analyze each specific relationship, we need to have a close look at each one separately. Starting off with the impact of academic trust on motivation, it can be said that we could find a weak-medium positive relationship, between these two 
variables. This relationship was found to be significant. $(r(73)=.41, p<0.00)$ Therefore we can say that if academic trust goes up, the student's motivation will increase. Due to the previously mentioned reasons, we can further interpret this to say that there is a positive correlation between academic trust and motivation that is not a result of sampling error, but rather a meaningful relationship in our data.

\begin{tabular}{|l|l|l|l|}
\hline $\begin{array}{l}\text { Table 2: Correlation between the types of trust (personal and academic) and } \\
\text { motivation or perceived performance. }\end{array}$ & Pcademic Trust & Personal Trust & Motivation \\
\hline & - & - & $.41\left(^{* *}\right)$ \\
\hline Academic Trust & - & - & $.46\left(^{* *}\right)$ \\
\hline Personal Trust & $.41\left(^{* *}\right)$ & $.46\left(^{* *}\right)$ & - \\
\hline Motivation & $.58\left(^{* *}\right)$ & $.47\left(^{* *}\right)$ & - \\
\hline Perceived Performance & ** Correlation is significant at the 0.01 level (2-tailed). \\
\hline
\end{tabular}

The second correlation to look at is the correlation between academic trust and perceived performance, which once again was a positive weak-medium relationship that was significant. ( $r(73)=.58, p<0.00)$. Henceforth it can be argued that when academic trust increases, the same happens to the dependent variable perceived performance. Thereby, it is possible to say that there is a positive correlation between academic trust and perceived performance, and that this correlation has not been affected by a sampling error.

Considering now, that in both cases academic trust had a positive relationship on the dependent variables, we decided to represent independent variable with both dependent variables in Graph 1. From the graph it can be said that both motivation and perceived performance have a positive correlation in relation to personal trust. However, the slopes of the linear curves vary, showing that they increase at different speeds.

The second to last correlation, to consider is the one between personal trust and academic trust. Just like for the academic trust ones, there is once again a positive medium-weak relationship that was calculated to be significant. $(r(73)=.46, p<0.01$ ) In other words, when personal trust increases, it implies that the student's motivation increases respectively. Taking this a step further, we can assume or interpret that there is a positive correlation between motivation and personal trust, and that this relationship comes from data that does not contain sampling errors.

Finally, one needs to examine the correlation between personal trust and perceived performance, which was once again a medium-weak positive connection, which was significant. ( $r(73)=.47, p<0.01)$ Interpreting this further it suggests that there is a positive correlation between personal trust and perceived performance that has not been affected by sampling error, and is genuinely a meaningful relationship in our data.

Similarly to the academic trust, we have also done a graph representing the impact of the independent variable personal trust on the two dependent variables - motivation and perceived performance. 
Figure 1. The impact of the independent variable Academic Trust (AT) on the dependent variables, motivation (MOT) and perceived.

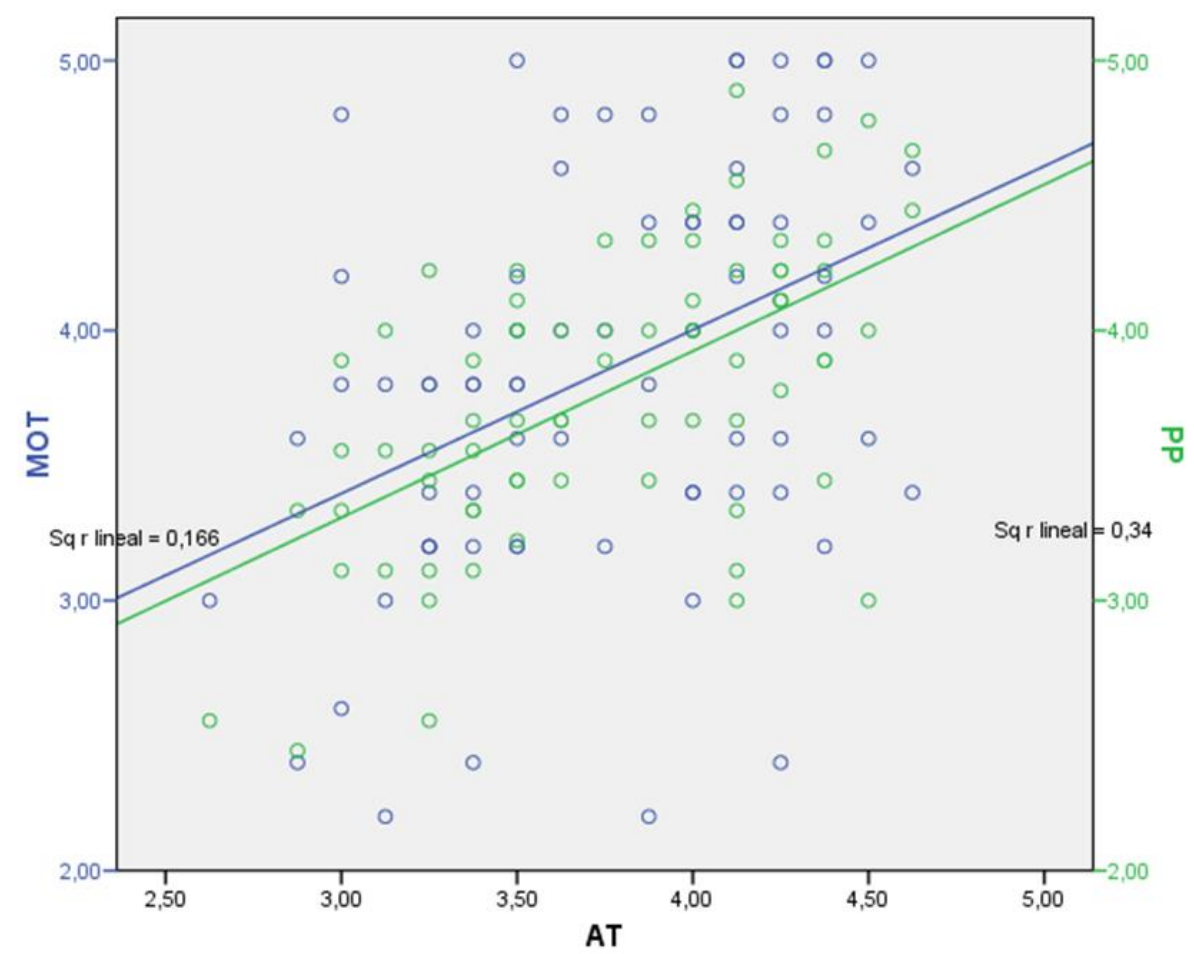

Figure 2. The impact of the independent variable Personal Trust (PT) on the dependent variables, motivation (MOT) and perceived performance (PP).

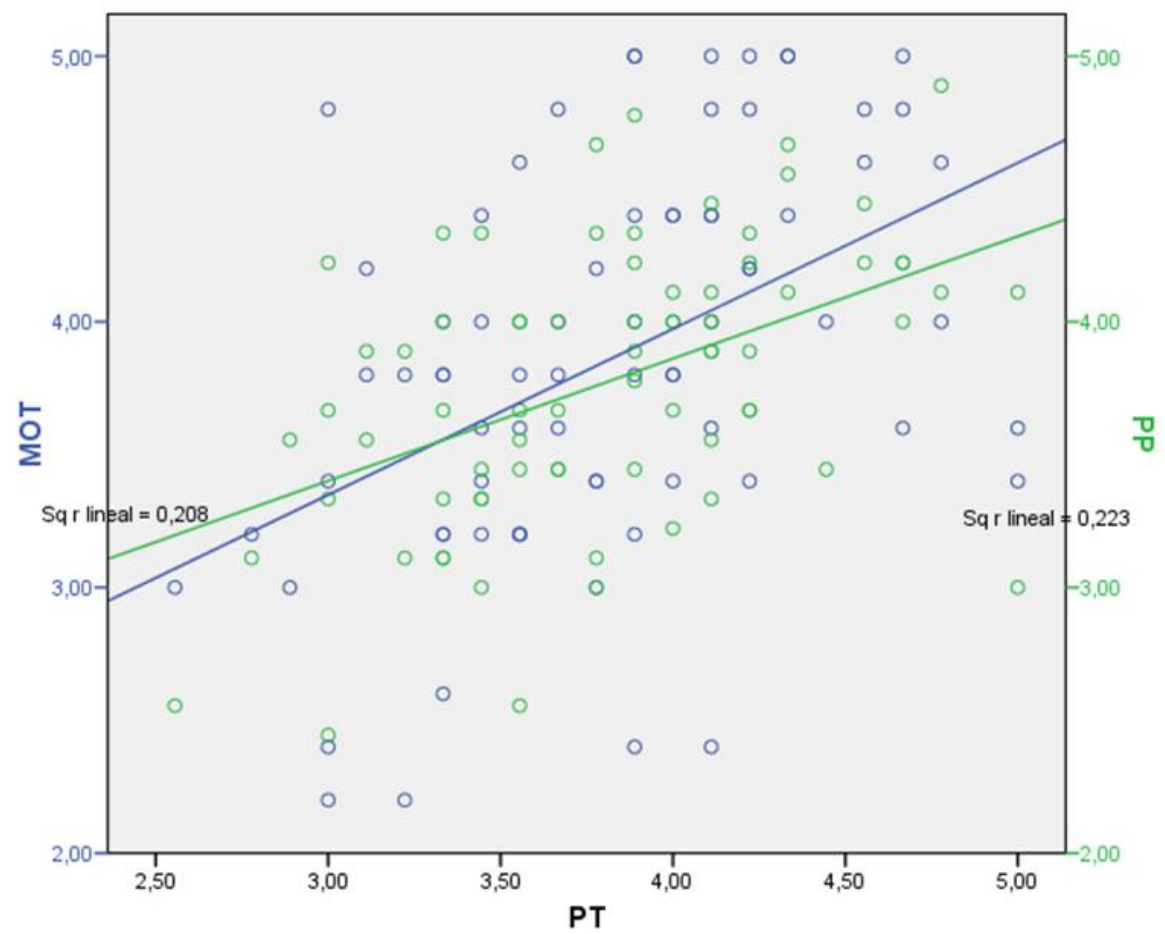




\section{DISCUSSION}

In this study, we examined the relationship between two types of trust-relationships and motivation or perceived performance. For each of the correlations, a weak-medium positive relationship could be found. This means we could only reject part of the null hypothesis, because not the full hypothesis was supported. Instead of finding a CR for both motivation and perceived performance, we found a linear one. Yet, we were right in predicting that academic trust positively impacts motivation and perceived performance in a positive linear relationship.

Having said that, it is vital to think about possible explanations for why we could not reject the full null hypothesis, that there was not a CR between personal trust and motivation or perceived performance. Maybe personal trust makes us build up a relationship in which the students become extremely ambitious because they feel like they need to do well for the professor. Maybe they are putting themselves under more pressure the better they get along with the professor and by this feel more motivated to do well and also perceive to be doing better. Besides different reasons for why our prediction was wrong, there might also be other methodological reasons for why we failed to find a CR between personal trust and perceived performance or motivation. To start off, there might have been experimental error. Even if the questions were taken from an already existing one and on top of that proofread and worded as precisely as possible, some of the questions might not have been clear enough for everyone. Also, it might be that the questions asked were not effectively evaluating what we were trying to measure. Maybe instead of asking for a value for the staff as a whole we should have considered the favorite and their least favorite professor. For Personal Trust especially, this could have been the reason for why we did not find a CR. In other words it might have been cancelled out by the professors that were less personally trust worthy. This is very likely due to the fact that we assume, not every student has the same amount of trust in every professor. That is normal according to the traditional trust theory because different level of interaction means different level of trust (Jones, 1996; 4-5). These differences could therefore be the reason for the linear instead of CR. Another, completely different interpretation would be that maybe it does not have to do with the student at all and that it might have been better to survey the professors about this rather than the students. Suggesting that it is the professor tends to give better grades and is more understanding, the better his trust-relationship with the student. This then could possibly influence the student's perceived performance, because he/she will be basing this on the marks he/she has been given and not on what he/she actually knows, simply because he/she will not be aware of this without the professor indicating it in any form. If that is the case then, there is a completely different issue, which is if a good student-professor trust relationship would influence the professor in making more positive evaluations of the student. In that case then, the higher the personal trust level, the higher the students' performance will be.

With regards to the level of personal trust, it can be said that basically all of these questions evolved around how much one shares and how close one is with a professor, which leads us to a possible participant error. Firstly, It is necessary to have clear that our study will focus the attention in higher education students because the trust relationship is completely different than with kids or teenagers. In today's society, being close to a professor and sharing more than necessary information with him/her is often seen negatively. People who are very close to the professors are often seen as being overly flattering or dependent. Hence, some of the participants might have felt more comfortable in indicating a lower level of personal trust, when their motivation and perceived performance was low, because they felt uncomfortable admitting that they are close with their professors. This would then result in the linear relationship rather than 
the CR we predicted. Moreover, the sample only included people of a certain age group (18-24), maybe participants in higher degrees of study are more open to evaluating their actual relationship towards their professors. Having said that though, it may be possible, to find differences, among professor-student relationship, depending on the student's degree of study and the type of education one has chosen (private vs. public). By this we mean that maybe the students trust relationship with a professor decreases from high school, over the Bachelor to the Masters, etc. Finally, the survey was completed online; therefore some participants might not have taken this too seriously and just answered any question without reading it properly. All data collected was based on a self-report only, which again could be the reason for inaccuracies.

With regards to what can be taken out of this study and applied to real life, it can be said that due to the previously mentioned positive correlations we have established that both academic and personal trust affect motivation and perceived performance. However, we have not mentioned the reasons behind there being a constantly growing linear relationship. Firstly, taking into account the independent variable of academic trust, we can relate it to motivation through various aspects. A student is obviously motivated when the professors who are teaching him/her are adapted to the job, which they are doing. If the professor explains the theories at a satisfactory and understandable level, then it is expected that the student will work harder. Our hypothesis did confirm the fact that student motivation keeps rising at a constant rate. There is no difficulty in analyzing this, as it is obvious that better teaching skills motivate students more. As mentioned previously, other studies have shown that a stronger student-teacher trust relationship increases motivation and academic performance (Goddard, Tschannen-Moran, \& Hoy, 2001: 5-7). This holds the same for perceived performance. Although perceived performance had lower absolute values than motivation, the rate at which they both increased was almost parallel. Furthermore, this suggests that the participants might have evaluated themselves more harshly on perceived performance as it encompasses a personal evaluation of skill. Therefore, regardless of the difference in absolute values, we can safely state that academic trust affects motivation and perceived performance in the same way.

On the other hand, this was not the case when evaluating personal trust's effect on the dependent variables. Firstly, the graph shows how motivation starts off relatively low with low levels of personal trust. However, the slope of the trend line for motivation is much higher than that for perceived performance. This implies that motivation increases at a much faster rate when it comes to personal trust. A consequence of this could be due to the fact that motivation is highly connected to the personal relationship a student has with his/her professor. Previously, it was mentioned that culturally sensitive pedagogy went hand in hand with the personal bonds a student shares with his/her teacher (Jackson, 1994: 298-304). Alternatively, perceived performance stands at a higher ground with low levels of personal trust. However, it increases at a slower pace than motivation. This could be due to the different types of authority perceived by the students regarding the two types of trust. A more academically trustworthy professor would probably motivate the students to work harder and even at a faster rate. This could be due to the fact that although the student is comfortable with the professor being good at what he/she does, the student does not feel close enough to be careless about the subject as he probably is also a harsh grader. In contrast, an enhanced personal trust relationship with a professor is much like working in a group with someone close. Although, the student might work harder in order to satisfy the peer's needs, he/she may feel that the judgment might be more lenient. This is primarily what was shown in the relationship between personal trust and perceived performance. 
On a separate note, we also wanted to consider briefly what connections there could be between both of the dependent variables and both of the independent variables. Obviously, motivation has an effect over perceived performance. Although, this effect was not graphed, as it was not what we were studying, considering the fact that students with higher levels of motivation will probably perform better in class will render alternative explanations. This is of course the idea that nor academic nor personal trust have full effect over a student's motivation and perceived performance. There are varying elements in a classroom, which can affect a student's work. The relationship between academic and personal trust is less apparent. It may be that a student with a strong personal trust relationship is biased as seeing that same professor as an academically trustworthy professor. On the contrary, a student that has a strong academic relationship to a professor might not have a strong personal relationship, as he/she wants to keep the relationship as professional as possible. Any of these alternatives suggest that the way in which the variables affect each other in our study could be due to an infinite amount of variables that we did not control.

This brings me to the internal consistency of each variable. Each variable was given an evaluation using Cronbach's Alpha. To begin with, academic trust received a 0.61 in reliability scores. This is the minimum requirement in order to consider the items used to represent academic trust a valid variable. Following was personal trust with a 0.77 alpha score. This score is more satisfactory and shows that the items used for personal trust are more representative. A similar result was shown for perceived performance with a score of 0.73 . The highest score was that of motivation which ended up having a 0.86 . We can infer that the fact that motivation was the variable with least items used to describe it caused it to be a more reliable measure.

\section{Limitations}

In sum, it can be said that this study should mainly be seen as another preliminary effort to study the affectivity and influence of professors trust relationship on their student's motivation and performance. Even though we attempted to create an objective and accurate study, there are still numerous improvements that could be made. Most of these have been mentioned when we discussed the reasons for why the null hypothesis could not be fully rejected. Yet, there are more consider. For example instead of considering random students from all over the world, clear studies within certain universities can be made. That way we would be looking at the same staff and the same system of education, resulting in more reliable and accurate data, because students as well as professors could be asked about the student's performance. Besides that it would also allow us to differentiate the staff rather than look at it as a whole. This is leading us to a next limitation, which is the fact it the survey was conducted online. Due to this, we could only ask for self-reports which might have been flawed, due to social desirability or simply because the participants might not have taken it too seriously. With regards to the sample itself it needs to be said that this was quite small. There were only 73 participants who answered the survey while the previous study looked at a total of 200 students. A further suggestion for a future study would be to consider the personality of the students, because it can be assumed that depending on the personality some will prefer one type of trust relationship more than the other and could still have the same performance or motivation.

Yet, we believe that this study has given us a clearer answer to the initial questions we had which were as follows: why is it that we are more motivated in some classes than in others? Why do we find some classes more fun and interesting than others? And what makes us perform so much better in some classes than in others? Henceforth, we do believe that this study has given us further insights into the topic, yet even more 
research needs to be done to improve the environment in universities and schools in order to enhance students' motivation and performance. To do so, our limitations should be considered and questions should be altered and improved. Instead of using an online interview, one could use a face-to-face interview or observational measures. Alternatively, this question could be examined experimentally instead of using a correlational design. For example, one group of students could be asked to share something personal with the experimenter before doing a standardized test. The standardized test would then be a measure of their performance, while the motivation of the student could either be observed or found out through a quick interview beforehand. The other group would in contrast to the other student not share anything with the experimenter but instead be given a list of achievements of that person. They would then also do a standardized test with a short interview before and after the test to evaluate motivation. The third group would then include both a shared experience and the list of academic achievement of the experimenter (professor) to see whether it might be the impact of both that is interplaying to enhance performance and motivation. Yet, this is only a suggestion and would obviously need to be thought through in a lot more depth, possibly being implemented in a one year longitudinal design.

Nonetheless, these results are provocative as they could give us an insight into how both academic and personal trust can impact a student's performance and motivation in University. This would not only be important for the question on how a working environment at schools and universities could be improved but also how working relationships in future jobs should be in order to have the best performance and motivation.

\section{REFERENCES:}

BAKER, J., GRANT, S., \& MORLOCK, L. (2008). The teacher-student relationship as a developmental context for children with internalizing or externalizing behavior problems. School Psychology Quarterly, Vol 23(1), Mar 2008, 3-15

BYRK, A., \& SCHNEIDER, B. (1996). Social trust: A moral resource for school improvement. In Wehlage,G. \& White, J. (eds.) Rebuilding the Village: Social Capital and Education in America. London: Palmer Press.

CORRIGAN, M. W., \& CHAPMAN, P. E. (2008). Trust in teachers: A motivating element to learning. Radical Pedagogy, 9(2), 3.

COTHRAN, D., \& ENNIS, C. (1997). Students' and teachers' perceptions of conflict and power. Teaching and Teacher Education, 13(5), 541-553.

ESHEL, Y., \& KOHAVI, R. (2003). Perceived classroom control, self-regulated learning strategies, and academic achievement. Educational Psychology, 23(3), 249260.

GODDARD, R. D., TSCHANNEN-MORAN, M., \& HOY, W. K. (2001). A multilevel examination of the distribution and effects of teacher trust in students and parents in urban elementary schools. The Elementary School Journal, 102(1), 317.

JACKSON, F. R. (1994). Seven strategies to support a culturally sensitive pedagogy. Journal of Reading, 37, 298-304.

JONES, K. (1996). Trust as affective attitude. Ethics 107, 4-25.

Pascual-Ezama, D., Sánchez-Martín, M.P. \& Delgado-Jalón, M. L. (2017). Estudiantes mejor informados: mejores resultados académicos. Revista de Contabilidad, 20(1), 47-54. 
K. Hamann, D. Maldonado, M.P. Sánchez, D. Pascual Ezama

ROSENFELD, L., RICHMAN, J., \& BOWEN, G. (1998). Low social support among at-risk adolescents. Social Work in Education, 20(4), 245-260.

SÁNCHEZ-MARTíN, M.P., PASCUAL-EZAMA, D., \& DELGADO-JALÓN, M. L. (2014):. El papel de la investigación como método para el desarrollo de conocimientos y competencias en el proceso de aprendizaje. Revista Universitaria Europea, 21, diciembre, 23-40.

STANGOR, C. (2011). Research methods for the behavioral sciences (4th ed.). Australia: Wadsworth Cengage Learning.

TSCHANNEN-MORAN, M., \& HOY, W. (2000). A multidisciplinary analysis of the nature, meaning, and measurement of trust. Review of Educational Research, 70(4), 547-593.

VAN MAELE, D., \& VAN HOUTTE, M. (2011). The quality of school life: Teacher-student trust relationships and the organizational school context. Social Indicators Research, 100(1), 85-100.

VAN PETEGEM, K., AELTERMAN, A.,VAN KEER, H., \& ROSSEEL, Y. (2006). The influence of student characteristics and interpersonal teacher behaviour in the classroom on students' wellbeing. Social Indicators Research, 85(2), 279-291.

WENTZEL, K. (1991). Relations between Social Competence and Academic Achievement in Early Adolescence. Child Development, 62(5), 1066-1078.

WOOTEN, A. G., \& MCCROSKEY, J. C. (1996). Student trust of teacher as a function of socio-communicative style of teacher and socio-communicative orientation of student. Communication Research Reports, 13(1), 94-100.

\section{APPENDIX}

\section{Appendix 1: ITS: Individualized Trust Scale}

\begin{tabular}{|l|l|l|l|l|l|l|}
\hline & 1 & 2 & 3 & 4 & 5 & \\
\hline Trustworthy* & & & & & & Untrustworthy \\
\hline Confidential & & & & & & Divulging \\
\hline Misleading & & & & & & Clear \\
\hline Respectful & & & & & & Disrespectful \\
\hline Honest & & & & & & Dishonest \\
\hline Unreliable & & & & & & Reliable \\
\hline Faithful & & & & & & Unfaithful \\
\hline Insincere & & & & & & Sincere \\
\hline Careful & & & & & & Careless \\
\hline Social & & & & & & Unsocial \\
\hline Fun & & & & & & Boring \\
\hline Unorganized & & & & & & Organized \\
\hline Experienced & & & & & & Inexperienced \\
\hline Strict & & & & & & Lenient \\
\hline Uncreative & & & & & & Creative \\
\hline Greedy & & & & & & Generous \\
\hline
\end{tabular}

* Participants complete the same questionnaire two times, with a two points of view respect to the professor: Academically and Personally. 
Appendix 2: LEM: Learner Empowerment Scale - altered to a Perceived Performance scale (PP)

The following questions were evaluated by the participants through a Likert scale; 1 being fully disagree, and 5 being fully agree:

1. I can make an impact on the way things are run in the classes.

2. I have the power to create a supportive learning environment in my classes.

3. I make a difference in the learning that is going on in my classes.

4. The work I do for my classes is a waste of my time

5. I feel that I can do the work assigned in my classes well.

6. I feel I can do well in my classes.

7. I do not think that I can do well on the assigned work in my classes.

8. I believe that I can achieve my goals in my classes.

9. I believe in my ability to do well in my classes.

\section{Appendix 3: SMS: Student Motivation Scale}

\begin{tabular}{|l|l|l|l|l|l|l|}
\hline & 1 & 2 & 3 & 4 & 5 & \\
\hline Motivated & & & & & & Unmotivated \\
\hline Uninterested & & & & & & Interested \\
\hline Involved & & & & & & Uninvolved \\
\hline Excited & & & & & & Unexcited \\
\hline Dreading it & & & & & & $\begin{array}{l}\text { Looking } \\
\text { forward to it }\end{array}$ \\
\hline
\end{tabular}

